\section{$\underset{\text { hommes }}{\text { \& migrations }}$}

\section{Hommes \& migrations}

Revue française de référence sur les dynamiques

migratoires

$1309 \mid 2015$

Le $3 e$ âge des migrants

\title{
Les Vietnamiens dans la Grande Guerre : des recrues pour l'industrie de l'armement
}

\section{Mireille Le Van Ho}

\section{(2) OpenEdition \\ Journals}

Édition électronique

URL : https://journals.openedition.org/hommesmigrations/3107

DOI : 10.4000/hommesmigrations.3107

ISSN : 2262-3353

Éditeur

Musée national de l'histoire de l'immigration

\section{Édition imprimée}

Date de publication : 1 janvier 2015

Pagination : 168-171

ISBN : 978-2-919040-30-8

ISSN : $1142-852 X$

\section{Référence électronique}

Mireille Le Van Ho, « Les Vietnamiens dans la Grande Guerre : des recrues pour l'industrie de l'armement », Hommes \& migrations [En ligne], 1309 | 2015, mis en ligne le 17 juillet 2015, consulté le 21 septembre 2021. URL : http://journals.openedition.org/hommesmigrations/3107 ; DOI : https:// doi.org/10.4000/hommesmigrations.3107 


\section{CHRONIQUES DE GUERRE}

\section{LES VIETNAMIENS DANS LA GRANDE GUERRE DES RECRUES POUR L'INDUSTRIE DE L'ARMEMENT}

MIREILLE LE VAN HO, archiviste paléographe.

L a guerre de 14-18 a provoqué la première vague d'émigration massive et organisée de main-d'œuvre vietnamienne en France, prise dans le flot des 850000 combattants et ouvriers coloniaux mobilisés par la France. Avant-guerre, l'immigration vietnamienne en France n'avait concerné qu'une centaine d'individus, boursiers du Gouvernement général, étudiants, mandarins en mission ou navigateurs recrutés par les compagnies maritimes. De 1915 à 1919, près de 90000 hommes, recrutés essentiellement parmi les paysans les plus pauvres du delta du fleuve Rouge, furent amenés en métropole et affectés à la logistique du front ou dans les usines de guerre pour 50 ooo d'entre eux. Immergés dans une industrie en pleine mutation dont ils ignoraient tout, ces "sujets français" furent soumis à une discipline militaire qui contribua pour beaucoup à leur mise au travail industriel.

L'Indochine apparaissait, au fur et à mesure de l'envoi des ouvriers français sur le front, comme un providentiel réservoir de main-d'œuvre, au moment où la France réorganisait son industrie de guerre. La construction de gigantesques usines d'armement impliquait une augmentation forcenée de la production et de la productivité. L'organisation des ateliers et l'introduction de nouvelles techniques de travail reposaient sur la mobilisation d'une grande quantité de maind'œuvre non qualifiée, permise par l'intervention de l'État dans tous les secteurs de l'industrie de guerre. En mai 1915, le recrutement des ouvriers fut pris en charge par l'État avec la nomination d'Albert Thomas au sous-secrétariat d'État à l'artillerie. Celui-ci concentra tous les pouvoirs de répartition, de répression et de contrôle de la main-d'œuvre et introduisit les originaires des colonies dans les usines de guerre, alors que l'administration coloniale y était largement opposée. Si les stéréotypes raciaux qui avaient cours autour de la constitution chétive des Indochinois et leur peu de goût supposé pour la guerre éclairent en partie leur affectation plus importante à l'usine qu'au front, les enquêtes menées sur le loyalisme de la garde indigène avantguerre et sur son implication récurrente dans les attentats nationalistes et anticolonialistes expliquent aussi cette défiance quant à leur emploi comme soldats. Quand le général Mangin présentait l'Afrique comme un réservoir de combattants pour la défense de la métropole, l'Extrême-Orient, Chine comprise, était conçu en haut lieu comme un réservoir de manœuvres, militarisés au nom de l'égalité de traitement avec les ouvriers français réquisitionnés, qui pouvaient à tout moment être renvoyés au front. Alors que les contrats des travailleurs européens recrutés à titre civil, Italiens ou Espagnols en particulier, firent l'objet de conventions comme celle passée en novembre 1916 entre la Confédération générale du travail (CGT) et l'Union générale des travailleurs espagnols', l'interdiction des syndicats dans les colonies et la militarisation des ouvriers coloniaux privèrent les instances syndicales d'un 
tel contrôle en amont. Les soldes², les primes ou la durée du travail ne furent jamais réellement alignées sur les conditions faites aux ouvriers européens. Ces différences sensibles de traitement expliquent le rejet durable que les ouvriers coloniaux subirent dans les usines, surtout après les mouvements de grève de 1917. Dès juillet 1916, l'Union des syndicats de la Gironde soulignait "les inconvénients qui peuvent survenir par suite de l'introduction en masse de la main-d'cuvre arabe et annamite, étant donné que cette catégorie d'ouvriers restera toujours éloignée des organisations syndicales 3 ."

\section{L'encadrement militaire des travailleurs vietnamiens}

Les ouvriers coloniaux constituèrent en moyenne $10 \%$ de l'effectif des usines d'armement, passé de 18000 avant-guerre à 170 ooo à la fin de 1917, mais les Vietnamiens, dans les poudreries du Sud-Ouest, représentaient à eux seuls $20 \%$ des effectifs à Bergerac ou à Toulouse 4 et jusqu'à $50 \%$ à la poudrerie de Saint-Médard-en-Jalles en Girondes. Le séjour en métropole et la découverte du travail industriel provoquèrent une rupture d'autant plus traumatisante avec la société d'origine qu'ils touchaient les hommes les moins affectés jusque-là dans la colonie par la modernisation et l'occidentalisation. L'encadrement militaire et le casernement obligatoire à proximité immédiate de l'usine réunissaient les conditions pour un apprentissage à marche forcée, comme le relevait Charles Picquenard ${ }^{6}$, chef de cabinet du ministre du Travail et conseiller d'Albert Thomas en 1916 : "Grâce à la discipline militaire à laquelle ils [les Indochinois] sont assujettis, ils remplissent généralement bien leur mission et la fiction d'un service militaire à accomplir fait de cette catégorie de travailleurs des ouvriers disciplinés et assidus au travail?."

La militarisation fut également décisive dans la réquisition des ouvriers coloniaux au moment des grandes grèves de 1917 et provoqua la défiance des ouvriers français qui demandèrent leur renvoi immédiat à la fin de la guerre au nom de la protection du travail national.

Les conditions de travail étaient particulièrement difficiles : affectés aux postes les plus dangereux de la production des explosifs, nitration et essorage des bandes de coton-poudre, les Vietnamiens étaient plus exposés aux accidents du travail en raison de leur ignorance du travail industriel et du barrage de la langue. Les maladies pulmonaires et les accidents du travail furent les principales causes d'hospitalisation ${ }^{8}$; la mortalité des ouvriers coloniaux fut deux fois plus élevée que celle des ouvriers français, comme l'établit l'enquête réalisée en février 1917 par l'Inspection médicale des usines de guerre : rotation moindre sur les postes de travail les plus pénibles, manque de linge de rechange, plus grande sensibilité au froid?.

\section{Une population sous surveillance}

Malgré l'encadrement militaire, l'envoi en métropole de ces milliers de paysans, confrontés à une modernité politique et économique inconnue en Indochine, ne laissa pas d'inquiéter les tenants des intérêts coloniaux, qui y virent un danger pour l'après-guerre. Albert Sarraut, de retour au Gouvernement général de l'Indochine en janvier 1917, forge alors, pour les contingents de travailleurs en France, un programme d'éducation et de formation limité aux besoins d'exploitation de la colonie et développé dans le cadre d'organes

2. Les avantages en nature de la nourriture et du logement dans les casernements étaient défalqués du montant de la solde. 3. AN F 7 13602, rapport du 16 juilet 1916 sur l'Union des syndicats de la Gironde. 4.6200 Vietnamiens étaient employés dans les établissements toulousains à la fin de la guerre. 5. ANOM, Indochine, Nouveau fonds, d. 226 et $244,1918$.

6. Haut fonctionnaire au ministère du Travail dans les années 1920, représentant de la France à l'Organisation internationale du travail (OIT) dans les années 1930, Charles Picquenard sera chargé par Léon Blum de rédiger le projet de loi sur les congés payés en juin 1936. 7. AN, 94 AP 135, note du 16 août 1916 sur le recrutement de main-d'œuvre coloniale et chinoise.

8. ANOM, SLOTFOM, X, 4, 1918. 9. AN, F 22 538, enquête de l'Inspection médicale sur les ouvriers des usines de guerre, février 1917. 10. ANOM, SLOTFOM X,4, note sur le Contrôle général des travailleurs et des tirailleurs indochinois, 1916. 


\section{CHRONIQUES DE GUERRE}

d'assistance et de surveillance créés pour l'occasion. Le Contrôle général des travailleurs et tirailleurs indochinois, une commission de censure postale spécifique et un réseau de foyers et d'associations d'encadrement de la vie quotidienne, animé par les intérêts commerciaux de la colonie, font des Vietnamiens les plus surveillés des contingents des colonies. Le Contrôle, créé par instruction ministérielle du 20 mars 1916 à l'intérieur du Service des travailleurs coloniaux, relève d'abord de la Direction des troupes coloniales, avant d'être rattaché

La transformation

des camps indochinois en mondes clos visait surtout à éviter aux ouvriers toutes "les perversions de contact" offertes par l'usine. le 18 avril 1917 au ministère des Colonies. La gestion des contingents reste à la charge de la Guerre, le Contrôle n'étant officiellement investi que d'une "mission de tutelle et d'observation des contingents" en vertu du "rôle naturel de guide et de tutrice ${ }^{10 "}$ dévolu à l'administration coloniale, représentée dans cette tâche par quelques-uns des "grands commis" de Sarraut et des mandarins qu'on a fait venir d'Indochine". Les rapports de tournées rédigés par les contrôleurs régionaux et les mandarins étaient repris dans les synthèses du contrôleur général et enrichis par les exceptionnels rapports de la Commission de contrôle postal. La connaissance approfondie des réalités indochinoises, que possédaient tous les contrôleurs, explique l'intérêt de ces rapports, complétés par ceux des mandarins, plus précisément chargés de recueillir les plaintes et les réclamations de leurs compatriotes. Leur nombre et leur qualité, inégalés pour les autres contingents coloniaux, prouvent la surveillance et l'encadrement très serrés dont les Vietnamiens ont fait l'objet pendant la guerre et fournissent à l'historien des sources incomparables sur leurs conditions de vie et de travail ainsi que sur l'évolution de leur état d'esprit' ${ }^{12}$. Des cours d'alphabétisation'13 et de loisirs organisés sont installés dans tous les groupements ouvriers, sous le patronage du Comité d'assistance aux travailleurs indochinois et de l'Alliance française. Mais la transformation des camps indochinois en mondes clos visait surtout à éviter aux ouvriers toutes "les perversions de contact" offertes par l'usine : fréquentation des femmes, sollicitations politiques et syndicales, mauvais esprit..., leitmotiv des rapports du contrôle postal.

\section{La remise en cause des cadres coloniaux}

Malgré une surveillance continue de leur vie quotidienne, la rencontre des travailleurs vietnamiens avec les ouvriers français et les femmes surtout, bouleversait les données d'un ordre colonial figé.

11. Parmi ces hauts fonctionnaires, Pierre Guesde, ancien directeur des Affaires indigènes à la résidence supérieure du Cambodge, puis chef de cabinet du ministre des Colonies de 1911 à 1914, prit la tête du Contrôle général en 1917 ; Jean Przyzluski, professeur aux Langues orientales, administrateur colonial en 1909, mais aussi chef de la section des Affaires indigènes au gouvernement général en 1911 et créateur des services secrets indochinois, assura le contrôle des contingents d'Île-de-France. Parmi les mandarins, on relève la présence de Nguyen Van Vinh, diplômé du Collège des interprètes, passé par l'administration indigène puis journaliste et éditeur, ardent promoteur de l'écriture romanisée et de la réforme de l'enseignement en Indochine ; francophile mais aussi membre de la Ligue des droits de l'homme, il n'hésita pas à dénoncer dans ses rapports les conditions matérielles indignes faites aux ouvriers, comme ce fut le cas au camp d'Aix-en-Provence (ANOM, SLOTFOM, I,9, rapport du 22 mars 1919). 12. Les papiers du Contrôle général des tirailleurs et travailleurs indochinois en France constituent le noyau originel du fond du Service de liaison avec les originaires des territoires français d'outre-mer (SLOTFOM), conservé aux Archives nationales d'outre-mer. Le 12 décembre 1923, lui succéda le Service de contrôle et d'assistance en France des indigènes des colonies (SCAFIC), chargé de la surveillance politique et du contrôle administratif des communautés africaine, malgache et vietnamienne en France. II prit le nom de Service de contrôle des indigènes par arrêté du 23 décembre 1941, puis celui de SLOTFOM en février 1948. 13. Parmi les $70 \%$ de recrues analphabètes à leur arrivée en France, $15 \%$ ont appris à lire et à écrire leur langue maternelle en métropole, 11 \% à s'exprimer en français et $4 \%$ à l'écrire (ANOM, Indochine Nouveau fonds 256, Alphabétisation au 1 $1^{\text {er }}$ mars 1918) 
La révélation de l'existence d'une population laborieuse chez les Français, la fréquentation des femmes - plus de $10 \%$ des recrues entretenaient encore une liaison à la fin de la guerre ${ }^{14}$ - et l'inversion réalisée du monopole sexuel exercé par les Blancs dans la colonie ont fourni aux Vietnamiens des motifs et des modèles de contestation de leur propre société. La lecture des lettres visées par le Contrôle postal permet de reconstruire la vision acérée et lucide de ces premiers émigrés sur la société française. De leur séjour, les Vietnamiens, peu convaincus de loyalisme, retinrent surtout que la puissance française pouvait être battue en brèche. Ils perdirent leur sens des hiérarchies traditionnelles au contact de la société française et de la désorganisation de l'aprèsguerre, en même temps que les plus instruits d'entre eux se livraient à une critique élaborée de l'exploitation à laquelle ils étaient soumis.

Même si la très grande majorité des recrues rentrent en Indochine entre l'armistice et 1920', la guerre avait déclenché des processus irréversibles et antagonistes dans la société indochinoise. La constitution en France d'une communauté vietnamienne, certes peu nombreuse mais à l'avant-garde de la lutte anticolonialiste dans le sillage du futur Hô Chi Minh, va pousser les autorités à transformer les structures du Contrôle en véritable service de police politique, ramifié en Indochine : en 1929, le Service de contrôle et d'assistance en France des indigènes des colonies (SCAFIC) ouvre un dossier pour 3675 des 5000 Vietnamiens présents en France $^{16}$. En Indochine, le régime colonial rejette la voie de la politique d'association proposée par les nationalistes modérés. Les intérêts coloniaux, s'inspirant des modes de recrutement initiés pendant la guerre, intensifient à partir de 1920 l'engagement de coolies du Nord vers les plantations du Sud et les colonies du Pacifique. Dans ce contexte de durcissement politique et d'exploitation économique accrue, les retours de France, s'ils n'ont pas directement influencé l'orientation politique des mouvements anticolonialistes, ont joué un rôle non négligeable dans le rajeunissement des mentalités, dans la contestation des privilèges des notables et dans la déstabilisation sociologique des villages. En 1930, ils participent aux révoltes paysannes et aux soviets du Nghê Tinh ${ }^{17}$, premières ripostes d'une société ébranlée par la guerre, marquée par la prolétarisation accélérée de sa paysannerie enclenchée lors des recrutements de 1916 pour la métropole, et sans issue politique dans un État colonial qui a refusé la voie réformiste, se condamnant à la répression et à la violence comme seuls instruments d'exercice du pouvoir. I

\section{Bibliographie indicative}

- Brocheux Pierre, "Une histoire croisée : l'immigration politique indochinoise en France (1911-1945)", in Hommes \& Migrations, $n^{\circ} 1253,2005$, pp. 26-37.

- Le Van Ho Mireille, Les Vietnamiens dans la Grande Guerre. 50000 recrues dans les usines françaises d'armement, Paris, Vendémiaire, 2014.

- Vu-Hill Kim Loan, Coolies into Rebels. Impact of World War I on French Indochina, Paris, Les Indes savantes, 2011. 